\title{
Australia Ae. aegypti mosquitoes are susceptible to a highly divergent and sylvatic dengue virus type 2 strain infection but are unlikely to transmit
}

\section{Paul Pickering}

Australian Defence Force Malaria and Infectious Disease Institute

\section{Leon Hugo}

QIMR Berghofer Medical Research Institute

Gregor J Devine

QIMR Berghofer Medical Research Institute

John G Aaskov

Queensland University of Technology

Wenjun Liu ( $\nabla$ wenjun.liu@defence.gov.au )

Australian Defence Force Malaria and Infectious Disease Institute https://orcid.org/0000-0002-15197091

Short report

Keywords: Ae. aegypti mosquitoes, Dengue virus, sylvatic transmission, vector competence

Posted Date: December 6th, 2019

DOI: https://doi.org/10.21203/rs.2.18361/v1

License: (c) (1) This work is licensed under a Creative Commons Attribution 4.0 International License.

Read Full License

Version of Record: A version of this preprint was published at Parasites \& Vectors on May 11th, 2020. See the published version at https://doi.org/10.1186/s13071-020-04091-5. 


\section{Abstract}

Background: Humans are the primary hosts of the dengue virus; However, sylvatic cycles of transmission can occur among non-human primates and human encroachment to forested regions can be a source of emergence of new strains. We reported the isolation of a highly divergent and sylvatic DENV-2 strain (QML22) from a dengue fever patient returning Australia from Borneo. The objective of the present study was to evaluate the vector competence of Australian Ae. aegypti mosquitoes for this virus.

Methods: Four-day old mosquitoes from two strains of Ae. aegypti from Queensland, Australia, were feed sheep blood meal containing $10850 \%$ cell culture infectious dose per $\mathrm{ml}$ (CCID50/ml) of either QML22 or an Australian epidemic DENV serotype 2 strain (QML16) isolated from a dengue fever patient in 2015. Mosquitoes were maintained at $28^{\circ} \mathrm{C}, 75 \%$ relative humidity and sampled at 7,10 and 14 days postinfection (DPI). Live virions in mosquito bodies (abdomen/thorax), legs and wings and saliva expectorates from individual mosquitoes were quantified using a Cell Culture Enzyme-linked Immunosorbant Assay (CCELISA) to determine infection, dissemination and transmission rates.

Findings: The infection and dissemination rates of the sylvatic DENV2 strain, QML22, within mosquitoes were significantly lower than that for QML16. While the titres of virus in the bodies of mosquitoes infected with either of these viruses were similar, titres in legs and wings were significantly lower in mosquitoes infected with QML22 at most time points although they reached similar levels by $14 \mathrm{DPI}$. QML16 was detected in 16\% ( $n=25)$ and $28 \%(n=25)$ of saliva expectorates at 10 and 14 DPI, respectively. In contrast, no virus was detected in the saliva expectorates of QML22 infected mosquitoes.

Conclusions: Australia urban/peri-urban Ae.aegypti species are susceptible to infection by the sylvatic and highly divergent DENV-2 virus QML22. However, our results indicate that replication of QML22 is attenuated relative to the contemporary strain QML16 and/or a salivary gland infection or escape barrier acts to prevent infection of saliva, potentially preventing onward transmission of this highly divergent virus in Australia.

\section{Background}

Dengue virus (DENV) has two ecologically and evolutionary discrete transmission cycles: sylvatic and urban endemic/epidemic [1]. The sylvatic cycle casts non-human primates as the host and several arboreal Aedes mosquito species as the transmission vectors [2, 3]. Alternatively, the urban endemic/epidemic cycle sees humans as the host and the peri-domestic Ae. aegypti mosquito as the principal vector. These two kinds of DENV cycles are evolutionary distinct and all four serotypes of endemic/epidemic DENV are considered to have evolved independently from the sylvatic DENV progenitors over the past 1,000 years. Sylvatic DENV1-4 strains from Malaysia and DENV-2 from West Africa have been reported to be able to spill over to infect humans causing similar or relatively milder dengue symptoms compared with the classic endemic/epidemic DENV infections [4-8] Whether sylvatic DENV strains can overcome adaptive barriers to infect peri-domestic Ae. aegypti mosquitoes, then enter 
the urban human-mosquito-human transmission cycle to cause secondary human infection (spillover epidemics), has been a source of debate for over a decade [1, 9-11]. Previous studies testing the ability of sylvatic DENV strains to infect Ae. aegypti have produced a confusing picture in which the susceptibility of Ae. aegypti to infection with sylvatic DENV-2 has ranged from refractory to almost $100 \%$ susceptibility [12-15]. Noticeably, none of the viruses studied were recovered from patients (i.e. they were not known to be able to infect humans). Instead, viruses were isolated from non-human primates and/or mosquitoes. In addition, these studies used virus dissemination to mosquito legs, wings and heads as a proxy for virus transmission capability, based on the assumption that if the virus were able to disseminate from midgut to these tissues, that the virus would have infected the salivary glands and transmission could occur $[15,16]$. The detection of infectious virus from mosquito saliva provides a more accurate proxy for transmission [17].

In 2016, we reported the isolation of a sylvatic strain of DENV-2, QML22, from a patient returning to Australia from Borneo [5]. The complete genome of QML22 is clearly divergent from Asian and West African lineages of sylvatic DENV-2. It has been reported that DENV susceptibility for Ae. aegypti varied geographically in Australia [18-20]. Here we determined the vector competence of two lines of Ae. aegypti responsible for urban transmission in Australia for this sylvatic strain of DENV by oral infection of mosquitoes with virus and analysis of infection within mosquito bodies, legs and wings and saliva.

\section{Methods}

Cells, viruses and mosquitoes

C6-36 (Ae. albopictus mosquito) cells were purchased from the American Type Culture Collection (ATCC) and cultured in 10\% v/v heat inactivated foetal calf serum (FCS, Life Technology, USA)/RPMI 1640 medium (Sigma, USA). The DENV-2 strain QML16 was isolated from a dengue fever patient in Australia and QML22 was isolated from a dengue fever patient returning to Australia from Borneo [5]. The virus strains were passaged three times in C6-36 cells to a titer around of $10^{8} \mathrm{CCID}_{50} / \mathrm{ml}$ and the cell culture supernatant was stored at $-80^{\circ} \mathrm{C}$ for further use.

Ae. aegypti colonies were established from collections in Townsville and Innisfail, north Queensland (QLD), Australia, and maintained within the Australian Defence Force Malaria and Infectious Disease Institute and QIMR Berghofer Medical Research Institute insectaries, respectively. Larvae were reared at a density of 200 larvae in $3 L$ of reverse osmosis water in plastic trays $(48 \times 40 \times 7 \mathrm{~cm})$ and fed ground TetraMin tropical fish food flakes (Tetra, Melle, Germany) at a rate of $0.25-1.0 \mathrm{mg} / \mathrm{larva} /$ day as development progressed. Pupae were transferred to cages $(30 \times 30 \times 30 \mathrm{~cm})$ for adult emergence. Adults were provided with $10 \%$ sugar solution on cotton wool pledgets which was withheld two day prior to virus feeding. Prior to feeding, mosquitoes (4 day-old) were deprived of sucrose solution for $24 \mathrm{~h}$.

Membrane feeding 
Approximately one hundred 3-5 day old mosquitoes were placed into $750 \mathrm{ml}$ containers with gauze covering the opening. DENV-2 strains QML16 and QML22 strains were mixed with defibrinated sheep blood to a titre of $10^{8} \mathrm{CCID}_{50} / \mathrm{ml}$ in C6/36 cells. The mosquitoes in containers were allowed $1 \mathrm{hr}$ to feed on the blood/virus mixtures through bovine ceacum membrane using an artificial feeding apparatus maintained at $37^{\circ} \mathrm{C}$, as previously described [21]. After feeding, mosquitoes were anaesthetized using $\mathrm{CO}_{2}$, placed on a Petri dish on ice and fully engorged females were separated from the unfed mosquitoes. The engorged mosquitoes were placed into the gauze covered containers, provided with cotton balls soaked with $10 \%$ sugar solution, and maintained within an Environmental Chamber (Panasonic) set at $28{ }^{\circ} \mathrm{C}, 75 \%$ relative humidity and $12: 12 \mathrm{~h}$ day:night ligiht schedule with 30 min dawn:dusk periods.

In vitro transmission assays

At 7, 10 and $14 \mathrm{dpi}$, female mosquitoes were anesthetized using $\mathrm{CO}_{2}$ and ice; legs and wings were removed. In vitro transmission assays were performed as previously described [22, 23]. For each mosquito, the proboscis was placed in a capillary tube containing $20 \mu \mathrm{l}$ of a 1:1 solution of $50 \%$ sucrose and FBS. After $30 \mathrm{~min}$, the contents were expelled into $0.25 \mathrm{ml} \mathrm{MD} \mathrm{(MD,} \mathrm{2 \%} \mathrm{FBS} \mathrm{in} \mathrm{RPMI} \mathrm{1640,} 50 \mu \mathrm{g} / \mathrm{ml}$ penicillin/streptomycin, $50 \mu \mathrm{g} / \mathrm{ml}$ gentamycin, $2.5 \mu \mathrm{g} / \mathrm{ml}$ Amphotericin B and $10 \mathrm{mM}$ HEPES).

Virus titre determination

Legs and wings samples and body samples from individual mosquitoes were placed into $2 \mathrm{ml}$ screw cap vial with $1 \mathrm{ml}$ MD with 4-5 zirconium silica beads. The samples were homogenized by shaking tubes for $1 \mathrm{~min} 30 \mathrm{~s}$ in a chilled block using a MiniBeadbeater-96 sample homogenizer (Biospec Products, Bartlesville, OK, USA) followed by centrifugation (twice at $17,000 \times \mathrm{g}, 10 \mathrm{~min}, 4^{\circ} \mathrm{C}$ )

Virus stocks and virus in mosquito samples were titrated using a Cell Culture Enzyme-linked Immunosorbant Assay (CCELISA) modified on the method of Broom et al [24]. Briefly, virus stocks and samples were ten-fold serially diluted and inoculated onto a monolayer of C6/36 cells grown in RPMI 1640 supplemented with L-glutamine, 5\% heat inactivated FBS, 1\% penicillin/streptomycin (Gibco Life Technologies, USA) and maintained at $30^{\circ} \mathrm{C}, 5 \% \mathrm{CO}_{2}$. After $7 \mathrm{~d}$ incubation, cells were fixed in acetone: methanol (1:1) for $1 \mathrm{hr}$ at $4^{\circ} \mathrm{C}$. Plates were air-dried and antigen was detected using a cocktail of antidengue monoclonal antibody hybridoma supernatants (4G2[25], 6B-6C1:3H5[26], at a ratio of 1:1:1) as the primary antisera, Horseradish peroxidase (HRP-) conjugated goat anti-mouse polyclonal antibody (DAKO, Carpinteria, CA, USA) (1:2000 in PBS-Tween) as the secondary antisera and 3,3',5,5'-

Tetramethylbenzidine (TMB) Liquid Substrate System for Membranes (Sigma-Aldrich, St. Louis, MO, USA) as the substrate. Wells with cell monolayers that stained blue were scored as positive for infection. The $\mathrm{CCID}_{50}$ was determined from titration endpoints as described everywhere [27] and expressed as the $\mathrm{CCID}_{50} / \mathrm{ml}$ in $\mathrm{C} 6 / 36$ cells.

Infection rate was defined as the proportion of mosquitoes with DENV positive bodies/total number of engorged mosquitoes. Dissemination and transmission rates were defined as the proportions of infected 
mosquitoes with positive legs/wings and salivary secretions/ the total number of engorged mosquitoes. We compared the virus titers and proportions using Mann-Whitney U-test and Chi square test.

Mosquito immunohistochemistry

Histological analysis of DENV infection within mosquitoes using indirect immunofluorescence assay (IFA), microscopy was performed based on the methods of described in our previous publication [22]. Briefly, mosquitoes with legs and wings removed were fixed in $4 \%$ paraformaldehyde/ $0.5 \%$ Triton $X$ for 12 $\mathrm{hr}$, dehydrated in xylol then a graded ethanol series, embedded in paraffin and 3-4 $\mu \mathrm{M}$ sections affixed to slides using standard histological procedures. Sections were incubated in Diva antibody retrieval solution (Biocare Medical, Concord, CA, USA) at $125^{\circ} \mathrm{C}$ for $5 \mathrm{~min}$ in a Biocare Medical Decloaking Chamber. Sections were cooled for 20 min and washed in PBS $+0.025 \%$ Tween 20 (PBST) twice for one minute each wash. Non-specific antibody binding was inhibited by incubating the sections in Biocare Medical Background Sniper $+2 \%$ BSA for 30 min. Excess Sniper/BSA was removed from the sections and the sections were incubated with undiluted $4 \mathrm{G} 2$ hybridoma supernatant for $2 \mathrm{hr}$ at room temp Sections were washed three times with PBST. Alexa Fluor donkey anti-mouse AF488 diluted 1:300 in PBS was applied for 30 minutes. Sections were washed three times with PBST before being counterstained with DAPI for 10 min, washed several times with PBS before being mounted.

\section{Results}

Fewer mosquitoes of Townsville Ae. Aegypti colony became infected when fed QML22 $(38.7 \%, n=75)$ virus containing blood meals compared to that of QML 16 containing blood meal fed $(75 \%, n=75)$

(Fig. 1a and b. Chi square test, $p<0.0001$ ), however body infection rates remained stable between 7 and 14 DPI time points for both virus strain.

Despite the lower body infection rates among mosquitoes fed on the QML22 strain, body titres of infected mosquitoes were not significantly different to mosquitoes infected with the QML16 strain (Fig. 1b) (Mann Whitney, $p>0.05$ ).

DENV-2 QML22 virus was first detected from mosquito legs and wings at $10 \mathrm{DPI}$, in contrast to the QML16 strain which infected legs and wings by as early as 7 DPI. Furthermore, QML22 disseminated to legs and wings in fewer mosquitoes that QML16 and virus grew to lower titres than the QML16 strain at 7 and $10 \mathrm{DPI}$ (Fig. $1 \mathrm{a}$ and $\mathrm{b}, \mathrm{P}<0.01$, chi squared test,). However QML22 reached similar titers to QML16 in legs and wings by $14 \mathrm{DPI}(\mathrm{P}>0.05$, chi square test, Fig. $1 \mathrm{~b})$.

No live virus was detected in saliva expectorates of mosquitoes fed on blood meals containing the QML22 strain at 7, 10 or 14 days post feeding. This was in contrast to mosquitoes fed on blood meals containing DENV2 QML16, which yielded 16\% (4/25) and 28\% (7/25) virus positive saliva samples at day 10 and $14 \mathrm{DPI}$, respectively. The virus titres of these samples reached a maximum of 1250 CCID50/mosquito. 
We repeated this procedure on a second line of Ae. aegypti established from mosquitoes collected $250 \mathrm{~km}$ away (Innisfail) several years after the Townsville line were established. Mosquitoes were fed on similar concentrations of QML16 and QML22 to those the Townsville strain. The infection rate for the QML22 virus within Innisfail Ae. aegypti was lower $(16 \%, n=25$ at $14 \mathrm{DPI})$ than that of the Townsville strain, while the infection rates of QML16 in both Ae. aegypti lines were similar $(72 \%, n=25$ for Innisfail and $75 \%, n=75$ for Townsville, $p<0.001$, Fig. $1 a \& b)$. In keeping with the first experiment, the titres of virus in the infected bodies was similar between mosquitoes fed QML16 and QML22 strains $\left(\sim 10^{7}\right.$ $\mathrm{CCID}_{50}$ /mosquito, Fig. $1 \mathrm{~b}$ ). This suggests that the Innisfail Ae. aegypti mosquitoes were less susceptible to infection with QML22 than those from Townsville. Low numbers of infected mosquitoes from Innisfail prevented statistical analysis.

Histological analysis of mosquitoes infected with dengue QML16 and QML22 supported the above results. Paraffin embedded sections were stained by indirect immunofluorescence employing anti-DENV envelope protein monoclonal antibody (4G2) and Alexa-fluor488-labelled anti-mouse immunoglobulin (green) [22] (Fig. 2). Disseminated virus infection was observed in $88 \%(n=25)$ mosquitoes $\geq 10 \mathrm{~d}$ post feeding on dengue QML16 and infection was observed in $50 \%$ of salivary glands $(n=6)$. In contrast, no virus dissemination had occurred beyond the midgut in any mosquitoes examined histologically at $\geq 10$ d post feeding DENV2 QML22 $(n=13)$.

\section{Discussion}

The importation of a pathogenic, transmissible and highly divergent DENV-2 genotype into Australia with a human population largely susceptible to DENV outbreaks, plus the endemic of the primary Dengue transmission vector Aedes aegypti in north Queensland[28], could have significant public health implications. Here we demonstrated that strains of Ae. aegypti from two population centres in north Queensland, Australia; Townsville and Innisfail, are susceptible and able to transmit a contemporary epidemic DENV-2 strain but they are much less susceptible to a highly divergent and sylvatic strain, DENV-2 QML22, and are potentially unable to transmit it.

Variable vector competence of Aedes aegypti populations from around the world for sylvatic DENV has been reported. A sylvatic strain of DENV-2 isolated from a mosquito in Senegal in 1965 was shown to infect $50-91 \%$ of Ae. aegypti among eight different Senegalese Ae. aegypti populations. Moreover, these results were achieved from blood meals containing substantially less virus than used in this study (approximately $10^{6-7} \mathrm{PFU} / \mathrm{ml}$ virus)[14]. Our infection rates more closely resemble those achieved when Ae. aegypti collected from Galveston, United States and from Bolivia became infected when fed on blood meals containing $10^{8}$ to $10^{9.5} \mathrm{TCID}_{50} / \mathrm{ml}$ of strains of sylvatic DENV-2 isolated from a mosquito in Burkina Faso, West Africa, and a sentinel monkey in Malaysia [29]. Variable vector susceptibility (0-26\% infection rate) was also observed in another study testing the vector competence of six Senegalese Ae. aegypti populations after feeding a $10^{6-7} \mathrm{PFU} / \mathrm{ml}$ virus of a sylvatic strain DENV-2 isolated from Senegal in 1999[12]. Noticeably, all these studies used dissemination to distal body tissues to determine the virus 
transmission potential based on an assumption that these mosquitos were capable of transmitting DENV if the virus had disseminated from midgut into the hemocoel $[15,16]$. In our experiment, we observed the dissemination of the QML22 strain into legs and wings but could not recover live virus from saliva at any time points. Our data also suggests that the vector competence of Australian Ae. aegypti mosquitoes for this sylvatic strain varies depending on the geographical origin of mosquito populations, even though they showed similar susceptibility for a contemporary epidemic DENV-2 QML16 strain. While it is possible that strains of Ae. aegypti from localities outside Australia may not have as stringent barriers to the dissemination and transmission of this highly divergent strain of DENV-2, it is unlikely that the barriers would be completely absent. Investigations to determine the mechanism underpinning the resistance of Ae. aegypti to infection with this sylvatic strain of DENV-2 are likely to be complex, given the enormous differences between the nucleotide and amino acid sequences of it and other strains of DENV-2 for which Ae. aegypti is known to be able to be a competent vector [5].

In order to transmit the virus to an uninfected human, DENV must counteract the mosquito innate immune system to replicate and disseminate through the mosquito before infecting saliva[30]. Several physiological 'barriers' to this dissemination have been hypothesised, including midgut infection and escape barriers (MIB and MEB) and salivary gland infection and escape bariers (SGIB and SGEB). Earlier studies have indicated that the MIB is a major determinant of $V C$ for Dengue virus [31, 32]. The lower body infection rate of QML22 (Fig. 1a) suggests a MIB might be the first obstacle for the highly divergent QML22 where the virus/cell-receptor interaction and internalization into the midgut epithelial cells is potentially less compatible to that of the QML16 strain. When the MIB was overcome, the QML22 strain reached body similar virus titers to the QML16 strain (Fig. 1b). However, lower dissemination rates and virus titers in legs and wings indicate that replication way be attenuated in comparison to the QML16 strain. Although the QML22 strain reached the same titre in legs and wings as QML16 at 14DPI (Fig. 1b), no live virus was detected in mosquito saliva by both CCELISA and immune-histological methods. This may indicate the presence of SGIB/SGEB preventing transmission. The relative importance of attenuated virus replication or physiological infection barriers remains to be determined.

The marked differences between VC of this highly divergent/primitive strain of DENV 2 (QML22) and a mainstream strain (QML16) suggest further studies with Ae. albopictus and arboreal strains of Ae. are also warranted, if colonies can be established, to determine whether other strains of Ae. aegypti also are poor vectors of QML22 or whether there is a gradient of competencies from arboreal to urban mosquitoes.

\section{Conclusions}

We demonstrated that both Ae. aegypti species from Townsville and Innisfail North Queensland are highly susceptible and able to transmit a contemporary epidemic DENV-2 strain but are much less susceptible to a highly divergent and sylvatic DENV-2 QML22 and potentially unable to transmit it. Our findings support a conclusion that sylvatic DENV is unlikely to enter urban human -mosquito-human transmission cycle to cause secondary human infection in Australia[33]. 


\section{Abbreviations}

CCELISA: Cell Culture Enzyme-linked Immunosorbant Assay; VC: vector competence (VC); DENV: Dengue virus; ATCC: American Type Culture Collection; QLD: Queensland; HRP: Horseradish peroxidase; CCID50: $50 \%$ cell culture infectious dose; IFA: indirect immunofluorescence assay; PBST: PBS+0.025\% Tween 20; DPI: Days post infection; FCS: Foetal bovine serum. TMB: Tetramethylbenzidine.

\section{Declarations}

\section{Acknowledgements}

We thank Clay Winterford (Histotechnology Facility QIMR Berghofer)

for his excellent support, and to Elise Kho (Mosquito Control Laboratory QIMR B) for assistance with mosquito rearing. LH was supported by a JT Wilson Fellowship from the Perpetual Foundation.

\section{Funding}

The work was funded by Australian Defence Force, a Perpetual JT Wilson

Fellowship (Leon Hugo).

\section{Availability of data and material}

The data supporting the conclusions of this article are included within the article. Raw data and materials are available from the corresponding author upon request.

\section{Authors' contributions}

Pickering and Hugo undertook the experiments and contributed equally to this study. GJD, JGA and WJL conceived and designed the study. All authors read, reviewed and approved the final manuscript.

\section{Authors' information}

PP and LH should be considered joint first authors.

Competing interests

The authors declare that they have no competing interests.

\section{Consent for publication}

Not applicable. 


\section{Ethics approval}

Not applicable.

\section{Author details}

1. Australian Defence Force Malaria and Infectious Disease Institute, Brisbane, Australia.

2. QIMR Berghofer Medical Research Institute, Brisbane, Australia.

3. Queensland University of Technology, Brisbane, Australia.

Disclaimer. The opinions expressed by authors contributing to this article do not necessarily reflect the opinions of the institutions with which the authors are affiliated.

\section{References}

1. Vasilakis N, Cardosa J, Hanley KA, Holmes EC, Weaver SC: Fever from the forest: prospects for the continued emergence of sylvatic dengue virus and its impact on public health. Nat Rev Microbiol $2011,9(7): 532-541$.

2. Vasilakis N, Holmes EC, Fokam EB, Faye O, Diallo M, Sall AA, Weaver SC: Evolutionary processes among sylvatic dengue type 2 viruses. J Virol 2007, 81(17):9591-9595.

3. Vasilakis N, Fokam EB, Hanson CT, Weinberg E, Sall AA, Whitehead SS, Hanley KA, Weaver SC: Genetic and phenotypic characterization of sylvatic dengue virus type 2 strains. Virology 2008, 377(2):296-307.

4. Carey DE, Causey OR, Reddy S, Cooke AR: Dengue viruses from febrile patients in Nigeria, 1964-68. Lancet 1971, 1(7690):105-106.

5. Liu W, Pickering P, Duchene S, Holmes EC, Aaskov JG: Highly Divergent Dengue Virus Type 2 in Traveler Returning from Borneo to Australia. Emerg Infect Dis 2016, 22(12):2146-2148.

6. Pyke AT, Moore PR, Taylor CT, Hall-Mendelin S, Cameron JN, Hewitson GR, Pukallus DS, Huang B, Warrilow D, van den Hurk AF: Highly divergent dengue virus type 1 genotype sets a new distance record. Sci Rep 2016, 6:22356.

7. Zeller HG, Traore-Lamizana M, Monlun E, Hervy JP, Mondo M, Digoutte JP: Dengue-2 virus isolation from humans during an epizootic in southeastern Senegal in November, 1990. Res Virol 1992, 143(2):101-102.

8. Saluzzo JF, Cornet M, Castagnet P, Rey C, Digoutte JP: Isolation of dengue 2 and dengue 4 viruses from patients in Senegal. Trans R Soc Trop Med Hyg 1986, 80(1):5.

9. Mota J, Rico-Hesse R: Humanized mice show clinical signs of dengue fever according to infecting virus genotype. J Virol 2009, 83(17):8638-8645.

10. Vasilakis N, Shell EJ, Fokam EB, Mason PW, Hanley KA, Estes DM, Weaver SC: Potential of ancestral sylvatic dengue-2 viruses to re-emerge. Virology 2007, 358(2):402-412. 
11. Gaye A, Wang E, Vasilakis N, Guzman H, Diallo D, Talla C, Ba Y, Dia I, Weaver SC, Diallo M: Potential for sylvatic and urban Aedes mosquitoes from Senegal to transmit the new emerging dengue serotypes 1, 3 and 4 in West Africa. PLoS Negl Trop Dis 2019, 13(2):e0007043.

12. Diallo M, Ba Y, Faye O, Soumare ML, Dia I, Sall AA: Vector competence of Aedes aegypti populations from Senegal for sylvatic and epidemic dengue 2 virus isolated in West Africa. Trans $R$ Soc Trop Med Hyg 2008, 102(5):493-498.

13. Diallo M, Sall AA, Moncayo AC, Ba Y, Fernandez Z, Ortiz D, Coffey LL, Mathiot C, Tesh RB, Weaver SC: Potential role of sylvatic and domestic African mosquito species in dengue emergence. Am J Trop Med Hyg 2005, 73(2):445-449.

14. Dickson LB, Sanchez-Vargas I, Sylla M, Fleming K, Black WCt: Vector competence in West African Aedes aegypti Is Flavivirus species and genotype dependent. PLoS Neg/ Trop Dis 2014, 8(10):e3153.

15. Moncayo AC, Fernandez Z, Ortiz D, Diallo M, Sall A, Hartman S, Davis CT, Coffey L, Mathiot CC, Tesh RB et al: Dengue emergence and adaptation to peridomestic mosquitoes. Emerg Infect Dis 2004, 10(10):1790-1796.

16. Gubler DJ, Nalim S, Tan R, Saipan H, Sulianti Saroso J: Variation in susceptibility to oral infection with dengue viruses among geographic strains of Aedes aegypti. Am J Trop Med Hyg 1979, 28(6):1045-1052.

17. Anderson SL, Richards SL, Smartt CT: A simple method for determining arbovirus transmission in mosquitoes. J Am Mosq Control Assoc 2010, 26(1):108-111.

18. Watson TM, Kay BH: Vector competence of Aedes notoscriptus (Diptera: Culicidae) for Barmah Forest virus and of this species and Aedes aegypti (Diptera: Culicidae) for dengue 1-4 viruses in Queensland, Australia. J Med Entomol 1999, 36(4):508-514.

19. Knox TB, Kay BH, Hall RA, Ryan PA: Enhanced vector competence of Aedes aegypti (Diptera: Culicidae) from the Torres Strait compared with mainland Australia for dengue 2 and 4 viruses. J Med Entomol 2003, 40(6):950-956.

20. Ye YH, Ng TS, Frentiu FD, Walker T, van den Hurk AF, O'Neill SL, Beebe NW, McGraw EA: Comparative susceptibility of mosquito populations in North Queensland, Australia to oral infection with dengue virus. Am J Trop Med Hyg 2014, 90(3):422-430.

21. Rutledge LC WR, Gould DJ: Studies on the feeding response of mosquitoes to nutritive solutions in a new membrane feeder. Mosq News 1964, 24:407-419.

22. Hugo LE, Prow NA, Tang B, Devine G, Suhrbier A: Chikungunya virus transmission between Aedes albopictus and laboratory mice. Parasit Vectors 2016, 9(1):555.

23. Hugo LE, Stassen L, La J, Gosden E, Ekwudu O, Winterford C, Viennet E, Faddy HM, Devine GJ, Frentiu FD: Vector competence of Australian Aedes aegypti and Aedes albopictus for an epidemic strain of Zika virus. PLoS Negl Trop Dis 2019, 13(4):e0007281.

24. Broom AK, Hall RA, Johansen CA, Oliveira N, Howard MA, Lindsay MD, Kay BH, Mackenzie JS: Identification of Australian arboviruses in inoculated cell cultures using monoclonal antibodies in ELISA. Pathology 1998, 30(3):286-288. 
25. Roehrig JT, Mathews JH, Trent DW: Identification of epitopes on the E glycoprotein of Saint Louis encephalitis virus using monoclonal antibodies. Virology 1983, 128(1):118-126.

26. Henchal EA, Gentry MK, McCown JM, Brandt WE: Dengue virus-specific and flavivirus group determinants identified with monoclonal antibodies by indirect immunofluorescence. Am J Trop Med Hyg 1982, 31(4):830-836.

27. Charretier C, Saulnier A, Benair L, Armanet C, Bassard I, Daulon S, Bernigaud B, Rodrigues de Sousa E, Gonthier $\mathrm{C}$, Zorn E et al: Robust real-time cell analysis method for determining viral infectious titers during development of a viral vaccine production process. J Virol Methods 2018, 252:57-64.

28. Naish S, Dale P, Mackenzie JS, McBride J, Mengersen K, Tong S: Spatial and temporal patterns of locally-acquired dengue transmission in northern Queensland, Australia, 1993-2012. PLoS One 2014, 9(4):e92524.

29. Young KI, Mundis S, Widen SG, Wood TG, Tesh RB, Cardosa J, Vasilakis N, Perera D, Hanley KA: Abundance and distribution of sylvatic dengue virus vectors in three different land cover types in Sarawak, Malaysian Borneo. Parasit Vectors 2017, 10(1):406.

30. Franz AW, Kantor AM, Passarelli AL, Clem RJ: Tissue Barriers to Arbovirus Infection in Mosquitoes. Viruses 2015, 7(7):3741-3767.

31. Mercado-Curiel RF, Black WCt, Munoz Mde L: A dengue receptor as possible genetic marker of vector competence in Aedes aegypti. BMC Microbio/ 2008, 8:118.

32. Salas-Benito J, Reyes-Del Valle J, Salas-Benito M, Ceballos-Olvera I, Mosso C, del Angel RM: Evidence that the 45-kD glycoprotein, part of a putative dengue virus receptor complex in the mosquito cell line C6/36, is a heat-shock related protein. Am J Trop Med Hyg 2007, 77(2):283-290.

33. Vasilakis N, Weaver SC: The history and evolution of human dengue emergence. Adv Virus Res 2008, 72:1-76.

\section{Figures}


(a)

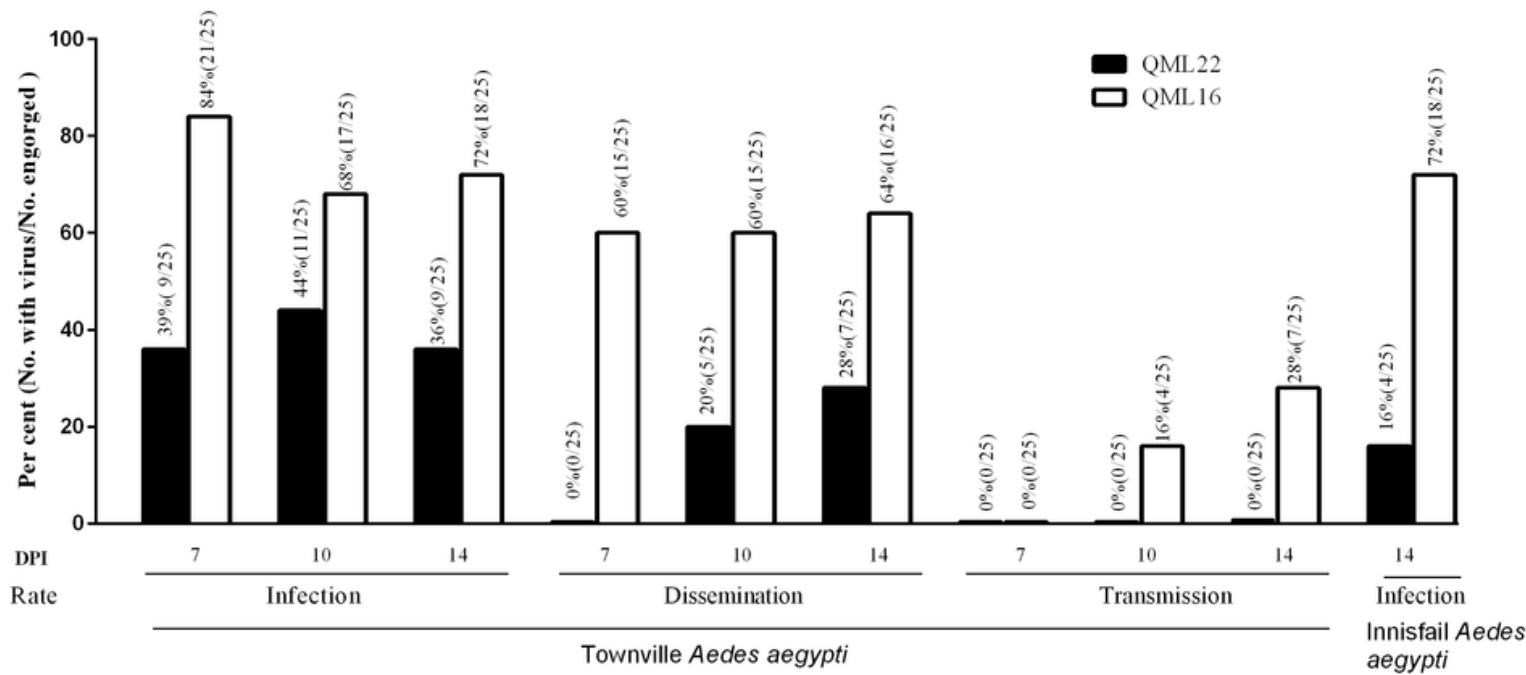

(b)

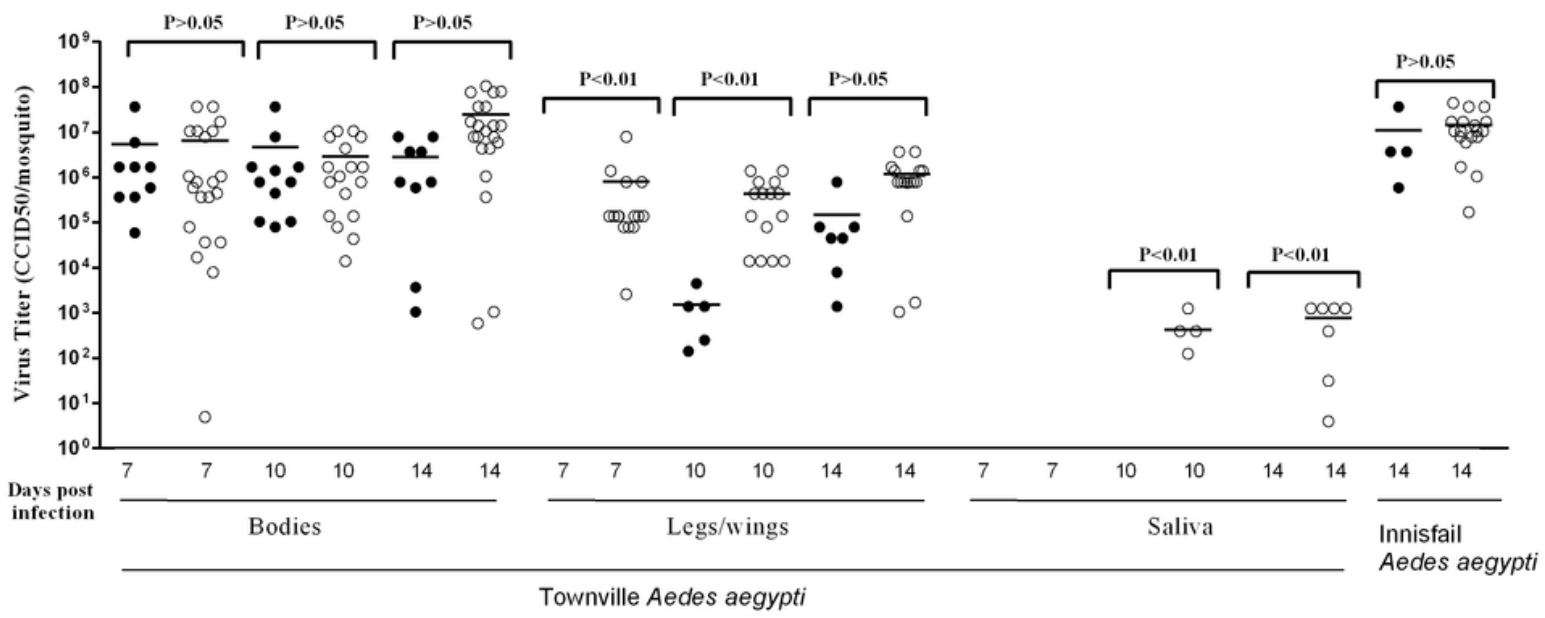

Figure 1

Infection rate, dissemination and transmission potential of DENV-2 QML16 (open symbols) and DENV-2 QML22 (closed symbols) in Ae. aegypti mosquitoes. (a) Infection, dissemination and transmission rates were calculated from the proportion of blood fed mosquitoes that developed a detectable DENV infection in the bodies, legs/wings and saliva, respectively. (b) Titres of virus in tissues from infected insects quantified by CCELISA in C6/36 mosquito cells. 
(a)

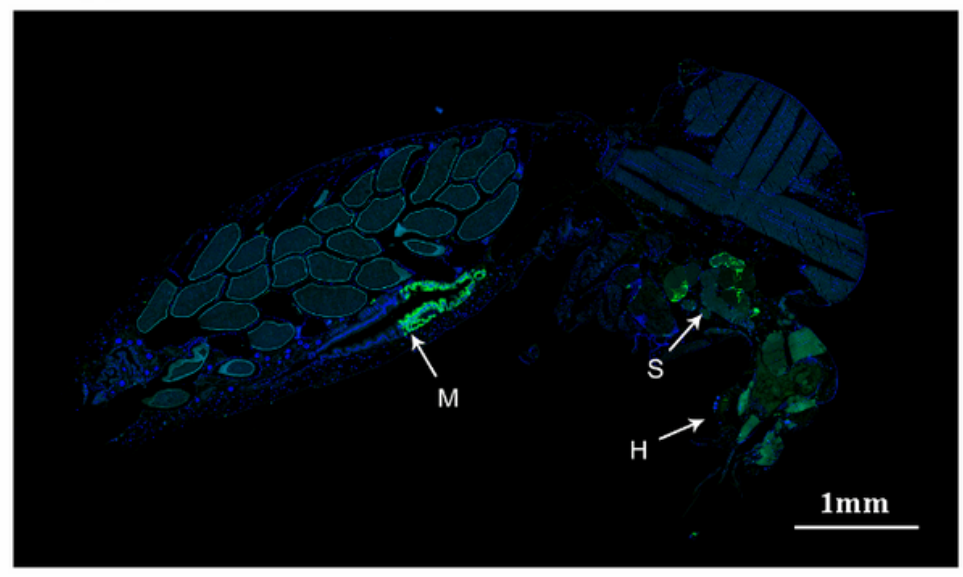

(b)

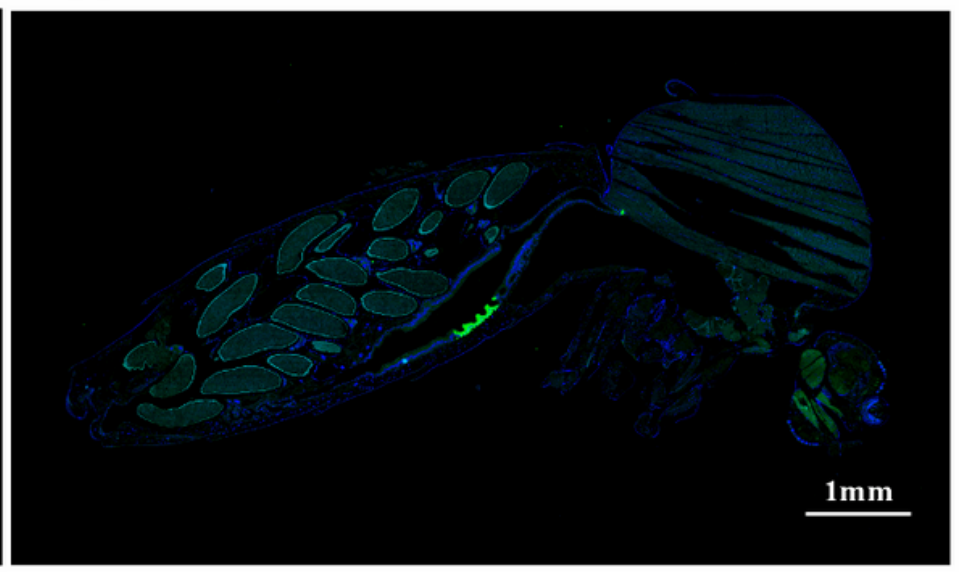

\section{Figure 2}

Midsagittal sections showing tissue distribution of dengue virus QML16 and QML22 strain infection within orally inoculated Aedes aegypti. Mosquitoes were examined for the distribution of DENV infection by immunofluorescence analysis of paraffin sections using an anti-Flavivirus Envelope protein monoclonal antibody and Alexa-fluor 488 conjugated secondary antibody for DENV (green) and DAPI staining for DNA (blue). A. Example of whole body staining of mosquitoes infected with DENV QML16 showing staining in head $(\mathrm{H})$, midgut $(\mathrm{M})$; and salivary glands $(\mathrm{S})$. B. Example of whole body staining of mosquitoes infected with DENV QML22 showing infection limited to the midgut. No staining was observed beyond midguts for mosquitoes inoculated with QML22. Scale bars $=1 \mathrm{~mm}$.

\section{Supplementary Files}

This is a list of supplementary files associated with this preprint. Click to download.

- Graphicalabstract.tif 